\title{
Simultaneous expression of Oct 4 and genes of three germ layers in single cell-derived multipotent adult progenitor cells
}

\author{
Kai-Hong Ji • Jun Xiong • Kai-Meng Hu • Li-Xing Fan • \\ Hou-Qi Liu
}

Received: 25 October 2007 / Accepted: 14 February 2008/Published online: 13 March 2008

(C) Springer-Verlag 2008

\begin{abstract}
Future application of adult stem cells in clinical therapies largely depends on the successful isolation of homogeneous stem cells with high plasticity. Multipotent adult progenitor cells (MAPCs) are thought to be a more primitive stem cell population capable of extensive in vitro proliferation with no senescence or loss of differentiation capability. The present study was aimed to find a less complicated and more economical protocol for obtaining single cell-derived MAPCs and understand the molecule mechanism of multi-lineage differentiation of MAPCs. We successfully obtained a comparatively homogeneous population of MAPCs and confirmed that single cell-derived MAPCs were able to transcribe Oct4 and genes of three germ layers simultaneously, and differentiate into multiple lineages. Our observations suggest that single cell-derived MAPCs under appropriate circumstances could maintain not only characteristics of stem cells but multi-lineage differentiation potential through quantitative modulation of corresponding regulating gene expression, rather than switching on expression of specific genes.
\end{abstract}

Keywords Multipotent adult progenitor cell · Oct 4 . Differentiation · Pluripotency

K.-H. Ji • J. Xiong $\cdot$ K.-M. Hu $\cdot$ L.-X. Fan $\cdot$ H.-Q. Liu $(\bowtie)$

Research Center of Developmental Biology,

Department of Histology and Embryology,

College of Basic Medical Sciences,

Second Military Medical University,

Xiangyin Road 800,

Shanghai 200433, People's Republic of China

e-mail: liuhouqismmu@yahoo.com.cn

\section{Introduction}

Bone marrow mesenchymal stem cells (MSCs) are the most-studied adult stem cells and have been widely used owing to their advantages in autografting and multi-lineage differentiation potential, which is also referred to as the plasticity of stem cells [1-4]. However, some studies in recent years indicated that MSCs might have no plasticity or only have a limited plasticity $[5,6]$ and that the in vivo multi-lineage differentiation of MSCs might be a result of their fusion with the host cells $[7,8]$. That is why, recently, people have been suspicious about the plasticity of MSCs. Some researchers think that the previously separated MSCs are actually a mixed cell population containing several kinds of stem cells with different differentiation potentials [9]. Therefore, how to isolate homogeneous MSCs with high plasticity becomes a ready task of researchers.

Isolation of MAPCs from adult bone marrows was firstly reported by Verfaillie's team [10-12]. Compared with MSCs, these cells were thought to be a more primitive cell population with partially overlapping ontogeny. Moreover, MAPCs have been proven to be capable of extensive in vitro proliferation with no senescence or loss of differentiation capability. A few researchers held that when embryonic stem cells differentiate into different somatic germ layers and tissue cells, some pluripotent cells remain in specific tissues for future use [13]; judging from their differentiation property, MAPCs should belong to this type of cell. Although the above hypothesis needs to be further verified, this subpopulation of pluripotent stem cells provides a new thought and may serve as a new cell source for tissue engineering. 
Based on the above understanding, we started our experiment with isolation of MAPCs from bone marrow of adult rats and then fully studied their differentiation potentials. MAPCs were isolated using a modified protocol of Verfaillie' team [10]. By screening for cells highly expressing Oct4 from clone-like clusters, we successfully obtained a comparatively homogeneous population of MAPCs with multi-lineage differentiation potential. The present study was aimed to find a less complicated and more economical protocol for obtaining single cell-derived MAPCs and understand the molecule mechanism of multilineage differentiation of MAPCs. Our observations confirmed that single cell-derived MAPCs were able to transcribe Oct4 and genes of three germ layers simultaneously, and differentiate into multiple lineages.

\section{Materials and methods}

Culture and clone expansion of MAPCs

Bone marrow was obtained from 4-week-old male SpragueDawley (SD) rats. With fat and red blood cells removed, the remaining cells were seeded at a density of $1 \times 10^{6}$ cells $/ \mathrm{cm}^{2}$ in $100 \mathrm{~mm}$ dishes coated with $10 \mathrm{ng} / \mathrm{ml}$ fibronectin (FN; Sigma-Aldrich, USA) and incubated at $37^{\circ} \mathrm{C}$ with $5 \% \mathrm{CO}_{2}$ in a fully humidified atmosphere. The expansion medium of MAPCs consisted of 60\% DMEM-LG (Gibco-Invitrogen, USA) and 40\% MCDB-201 (Sigma), with $2 \%$ fetal bovine serum (FBS; Gibco-Invitrogen), 1× insulin/transferring/selenium (ITS), $1 \times$ linoleic acid bovine serum albumin (LABSA), $10^{-9} \mathrm{M}$ dexamethasone (Dex), $10^{-4} \mathrm{M}$ ascorbic acid 2-phosphate (all from Sigma-Aldrich), $100 \mathrm{U} / \mathrm{ml}$ penicillin, 1,000 U/ml streptomycin (Gibco-Invitrogen), $10 \mathrm{ng} / \mathrm{ml}$ EGF (Sigma-Aldrich), $10 \mathrm{ng} / \mathrm{ml}$ PDGF-BB (R\&D Systems), and $10 \mathrm{ng} / \mathrm{ml}$ LIF (Chemicon International, USA). The non- adherent cells were removed by medium change at $24 \mathrm{~h}$ and every 3 days thereafter until $100 \%$ confluence was reached. Cells were passaged once with $0.25 \%$ trypsin-ethylenediaminetetraacetic acid (EDTA; Gibco-Invitrogen) and the passage 1 (P1) cells were replated at a 1:2 dilution under the same culture condition. After being passaged for at least four generations (P4), cells were seeded on a 96-well plate coated with $10 \mathrm{ng} / \mathrm{ml} \mathrm{FN}$ at a density of 0.5 cell/well by limited-dilution method in expansion medium. The wells containing more than one cell under a phase-contrast microscope were discarded. When cells grew to $40-50 \%$ confluence, they were pipetted from one well, seeded to one of the 24 wells, and then serially reseeded to a six-well plate, $60 \mathrm{~mm}$ dish, and $100 \mathrm{~mm}$ dish in the presence of $0.25 \%$ trypsin-EDTA. When cells reached a density of $4-8 \times$ $10^{3}$ cells $/ \mathrm{cm}^{2}$ in $100 \mathrm{~mm}$ dish, they were replated at a $1: 3$ dilution, and the fastest-growing clone was selected after being passaged for 20 times.

Total RNA isolation and RT-PCR analysis

Total RNA was extracted from the clonal cells using RNA Mini kit (Huashun, China). First-strand cDNA was synthesized with total RNA using a mixture of oligo (dT)12-18 and random hexamers (Roche Diagnostics, Germany) primers with AMV (Promega, USA) and Superscript II RNase H Reverse Transcriptase (Invitrogen, Germany). Polymerase chain reaction (PCR) was conducted with approximately $50 \mathrm{ng}$ cDNA for amplification of the following marker genes: pluripotent marker Oct-4, endodermal marker lanosterol-14a-demethylase (CYP 51), mesodermal marker SM22 $\alpha$ and GATA-4, and ectodermal marker $N$-methyl-Daspartic acid (NMDA) glutamate binding protein. The housekeeping gene encoding $18 \mathrm{~S}$ was used as an internal control. The PCR primers are listed in Table 1. After initial denaturation at $98^{\circ} \mathrm{C}$ for $3 \mathrm{~min}, \mathrm{PCR}$ amplification was
Table 1 Specific marker genes of three germ layers [14-16]

\begin{tabular}{llccc}
\hline Genes & Primers(5'-3') & $\begin{array}{c}\text { Product } \\
\text { size(bp) }\end{array}$ & Location & Layer \\
\hline Oct-4 & $\begin{array}{c}\text { Forward: CGCCAGAAGGGGAAAAGA } \\
\text { Reverse: CAGGAAAAGGGACCGAGTAG }\end{array}$ & 176 & & \\
CYP 51 & $\begin{array}{l}\text { Forward:ATCCTGACCGCTACCTACA } \\
\text { Reverse: GGCTTCCCTGAAATCCTA }\end{array}$ & 461 & Liver & Endoderm \\
SM22 $\alpha$ & $\begin{array}{l}\text { Forward:GTCCACAAACGACCAAGC } \\
\text { Reverse: GTTCTCAGGCACCTTCACT }\end{array}$ & 279 & Muscle & Mesoderm \\
NMDA & $\begin{array}{l}\text { Forward: TGAGCCCACCAGAAAAGG } \\
\text { Reverse: ACTGCTTTGCCCTCCACC }\end{array}$ & 625 & Brain & Ectoderm \\
GATA-4 & $\begin{array}{c}\text { Forward: TCCCCACAAGGCTATCCA } \\
\text { Reverse: CCGAAGAAGGTCACGAGGT }\end{array}$ & 321 & Heart & Mesoderm \\
& $\begin{array}{l}\text { Forward: CAAGAACGAAAGTCGGAGGTTCG } \\
\text { Reverse: TTATTGCTCAATCTCGGGTGGCTG }\end{array}$ & 460 & & \\
\hline
\end{tabular}


performed with Sawady Taq-DNAPolymerase (Takara Bio, Japan) at $95^{\circ} \mathrm{C}$ for $40 \mathrm{~s}$ followed by $28-35$ cycles, with each cycle consisting of annealing at $55-60^{\circ} \mathrm{C}$ for $40 \mathrm{~s}$, and a final extension at $72^{\circ} \mathrm{C}$ for $40 \mathrm{~s}$. PCR products were subjected to $1.5 \%$ agarose gel electrophoresis, and the bands were visualized by ethidium bromide and photographed with Chemi Doc XRS (Bio-Rad Laboratories, Fudan, China). Each experiment was performed in triplicate.

Immunocytofluorescence and fluorescence-activated cell sorter analysis

Clonal cultured MAPCs were fixed with $4 \%$ paraformaldehyde for $4 \mathrm{~min}$ at room temperature. After being blocked with phosphate-buffered saline (PBS) containing 2\% BSA, cells were permeabilized with $0.1 \%$ Triton-X100 for $10 \mathrm{~min}$. Slides were incubated sequentially overnight at $4{ }^{\circ} \mathrm{C}$ with the following primary antibodies: CD71 (1:50, Santa Cruz, USA), Vimentin (1:200, DAKO, USA), $\alpha$-SMA (1:200, Boster Biotechnology, China), and SSEA-1(1:50, Santa Cruz, USA); then cells were incubated for $40 \mathrm{~min}$ at room temperature with fluorescein isothiocyanate (FITC) or Cy3-coupled IgG secondary antibody (1:500, Jackson), stained with DAPI (Sigma-Aldrich), and observed under a fluorescence microscope (BX41TB, Olympus, Japan).

For fluorescence-activated cell sorter (FACS) analysis, cells pelleted were incubated on ice for $30 \mathrm{~min}$ with FITC- or PE-conjugated monoclonal antibodies against CD34, CD44, CD45 (Becton-Dickinson, CA), and MHC-I (Abcam, UK). After two washes with cold PBS, the labeled cells were analyzed by a FACStar flow cytometer (Becton Dickinson, CA, USA).

In vitro differentiation of MAPCs

To induce differentiation, clonal cultured MAPCs were cultured in the media containing no FCS, EGF, PDGF-BB, or LIF unless otherwise indicated. All the experiments were repeated at least three times.

Adipogenic differentiation of MAPCs MAPCs were seeded at a density of $3 \times 10^{4}$ cells $/ \mathrm{cm}^{2}$ in six-well plates, allowed to grow confluence, and cultured for another 3 days. Subsequently, cells were allowed to differentiate for 14 days in the expansion medium of MAPCs containing $0.5 \mathrm{mM}$ 3-isobutyl-1-methylxanthine (Serva Electrophoresis, Germany), $100 \mathrm{nM}$ Dex, $60 \mu \mathrm{M}$ indomethacin, and $10 \mu \mathrm{g} / \mathrm{ml}$ insulin. At the end of the culture, cells were fixed with $10 \%$ formaldehyde (Shenggong, China) for $10 \mathrm{~min}$ and were stained with fresh Oil Red O (Sigma-Aldrich) for $2 \mathrm{~h}$.

Osteogenic differentiation of MAPCs MAPCs, at a density of $2 \times 10^{4}$ cells $/ \mathrm{cm}^{2}$, were induced with osteogenic medium containing $10^{-8} \mathrm{M}$ Dex, $2 \times 10^{-4} \mathrm{M}$ ascorbic acid and $7 \times$
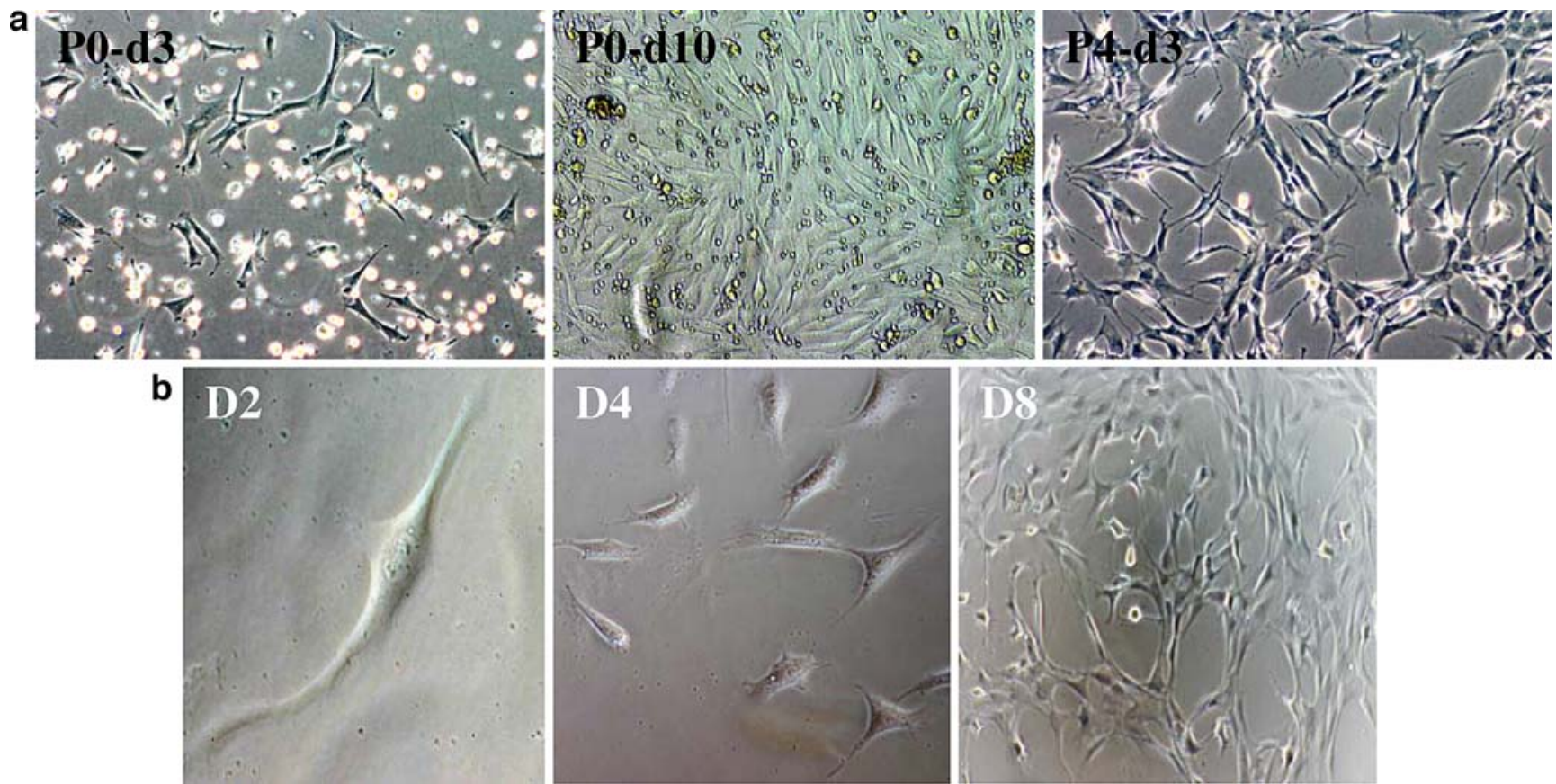

Fig. 1 Morphology of isolated MAPCs. a Phase-contrast micrographs of MAPCs at day $3(d 3)$, day $10(d 10)$ of primary culture $(P 0)$ and $P 4$ at day $3(d 3)$ after passages (original magnification $100 \times$ ). b MAPCs

cloned by limiting dilution. A single cell adherent to the plate in one well proliferated in the primary culture for 2 days $(D 2), 4$ days $(D 4)$, and 8 days $(D 8$; original magnification $\times 400)$ 
$10^{-3} \mathrm{M}$ glycerolphosphate for 2 weeks. NBT/BCIP staining was used to analyze alkaline phosphatase (AKP; all from Sigma-Aldrich) expression during MAPCs differentiation. Meanwhile, cells were immunocytochemically stained with osteopontin to detect osteogenic differentiation of MAPCs.

Neuroectodermal differentiation of MAPCs MAPCs were plated at a density of $1 \times 10^{4}$ cells $/ \mathrm{cm}^{2}$ on $\mathrm{FN}$ in a basal medium containing $100 \mathrm{ng} / \mathrm{ml}$ basic fibroblast growth factor (bFGF; R\&D Systems). The cells were allowed to differentiate for 14 days and then immunofluorescently stained for GFAP $(1: 100)$ and TAU $(1: 100$, both from Boster Biotechnology, China).

Hepatocyte differentiation of MAPCs MAPCs were plated at $2.2 \times 10^{4}$ cells $/ \mathrm{cm}^{2}$ on plastic chamber slides coated with $2 \%$ Matrigel in a basal medium supplemented with $10 \mathrm{ng} / \mathrm{ml} \mathrm{FGF-4}$ and $20 \mathrm{ng} / \mathrm{ml}$ HGF (both from R\&D Systems). After 14 days, immunofluorescent staining for albumin (1:500, DAKO, USA) was performed as described above.

\section{Results}

Stable in vitro proliferation and expansion of clonal cultured MAPCs

On the third day of primary culture, very few trianglelike cells adhered to the culture surface under a phase contrast microscope, coexisting with plenty of hematopoietic cells, which were round in shape and small in size, shining under the microscope (Fig. 1a, P0-d3). During the fourth to seventh day of culture, the trianglelike cells gradually increased and had a typical colony growth, with an obvious three-dimensional appearance and growth circle. The colony cells grew confluent and became morphologically homogenous after 7-10 days (Fig. 1a, P0-d10). After treatment with trypsin, the cultured cells no longer grew in clusters, but in a homogeneous manner (Fig. 1a, P4-d3).

Single-cell clonal culture was performed by infinite dilution technique. Thirty percent of single cell-derived MAPCs formed larger clones during culture (Fig. 1b), and six cell clones (7F\#, 4G\#, 6E\#, 4F\#, 7C\#, and 10D\#) were obtained in the following expansion. When being cultured at an extremely low density $\left(250\right.$ cells $\left./ \mathrm{cm}^{2}\right)$, this six-cell population still demonstrated strong capability of proliferation, with the doubling time being about 24-36 h. P20 cells still possessed the typical properties of MAPCs: polygonal-shaped, with larger nuclei, vacuoles around the nuclei, and sparse cytoplasm (Fig. 1b, D2, D4).
Expression of Oct4 and genes of three germ layers in single cell-derived MAPCs

The expression of self-renewal gene Oct4 was detected in the six cell clones after being passaged for more than 20 times. All the six cell clones were found to have different levels of Oct4 expression (Fig. 2a). Specific markers of the three germ layers were detected in the three cell clones (7F\#, 4G\#, and 10D\#), which strongly expressed Oct4. The specific markers included CYP51 (present in the liver of adults) for endoderm, SM22 $\alpha$ and GATA4 (present in the skeleton muscle the heart of adults) for mesoderm, and NMDA (present in the brain of adults) for neuroectoderm. As for the markers for the three germ layers, 4G\# clone had a very weak expression of CYP51 and all the rest clones had high expression of their corresponding markers (Fig. 2b), especially for single cell-derived MAPCs-10D\#. Therefore, we subjected single cell-derived MAPCs-10D\# to further experiments.

a 7F\# 4G\# 6E\# 4F\# 7C\# 10D\# M
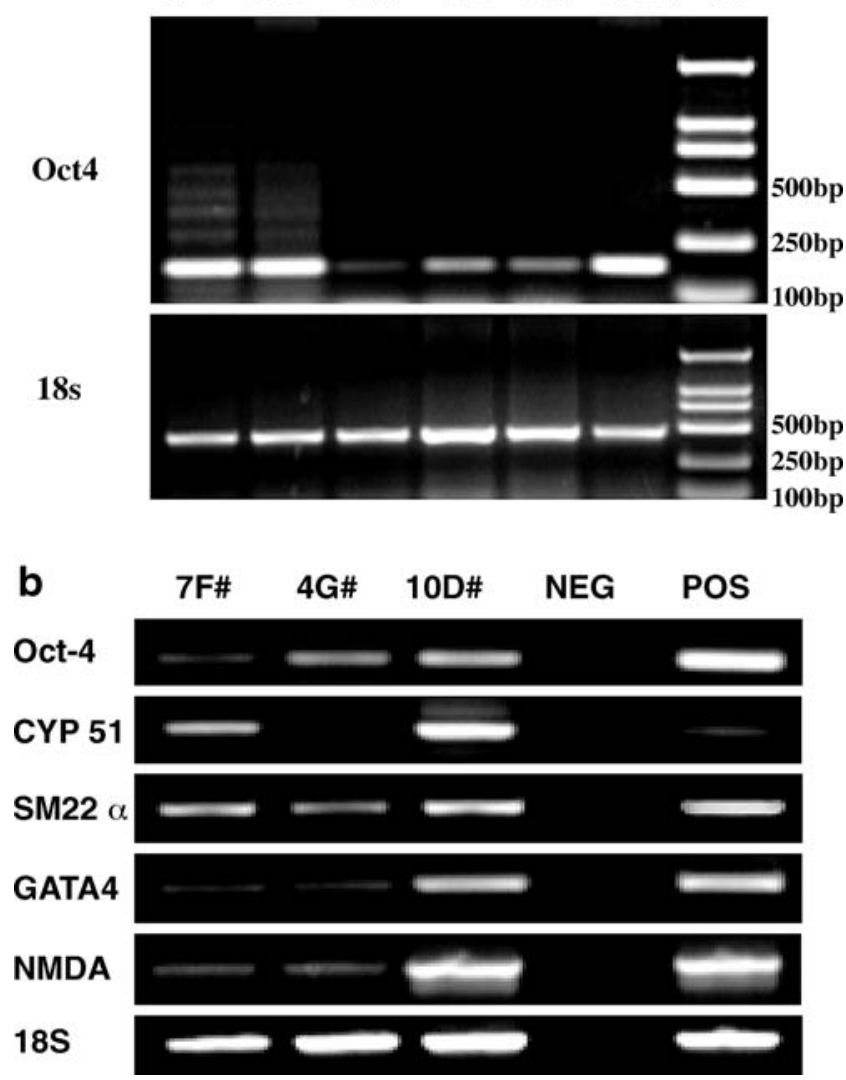

Fig. 2 RT-PCR analysis of expression of Oct-4 and specific markers for three somatic germ layers. a Oct- 4 was highly expressed in six cell clones. b CYP 51, SM22 $\alpha$, GATA4, and NMDA were positive in three cell clones. NEG Negative controls, POS positive controls for CYP 51 (fetal liver), SM22 $\alpha$ (fetal smooth muscles), GATA4 (fetal heart), and NMDA and Oct-4 (fetal brain tissues; $n=3$ ) 
Identification of molecular markers in single cell-derived P20 MAPCs-10D\#

Single cell-derived P20 MAPCs-10D\# was chosen for immunofluorescence assay. It was found that it expressed CD71 (a surface antigen of stem cells), Vimentin (a stromal cell skeleton protein), $\alpha$-SMA (a marker of early smooth muscle cells), and SSEA-1 (a marker for more primitive stem cells; Fig. 3a), suggesting that it still harbored the surface antigen of stem cells, the stromal cell skeleton protein, and the marker of early smooth muscle cells.

The results of flow cytometry showed that 10D\# clone did not express CD45 or CD34 (markers for hematopoietic stem cells). For the expression of CD44, the stromal cell marker, and MHC I, the major histocompatibility complex class I antigens, MAPCs were all negative (Fig. 3b).

Differentiation potential of single cell-derived P20 MAPCs-10D\# into three somatic germ layers consisting of osteoblasts, adipocytes, neurons, and hepatocytes

Single cell-derived P20 MAPCs were seen to have strong refractive oil drops around the nuclei on as early as the eighth day under the adipogenic condition, and the oil drops gradually increased and fused into larger ones with the prolongation of the induction time (Fig. 4a, 1). Twentyone days after induction with osteoblastic medium, AKP staining of MAPCs showed purple-bluish deposits in the cytoplasm (Fig. 4a, 2), and immunocytochemistry staining was positive for osteopontin (Fig. 4a, 3). Fourteen days after MAPCs were directed to differentiate into neuronal cells in vitro, cell morphology underwent obvious changes: the cytoplasm was shrinking, and bipolar or multipolar processes were seen growing out from the spindle-shaped cells (Fig. 4b, 1). Immunofluorescence staining showed the presence of Tau protein, the specific marker of neurons (Fig. 4b, 2), and GFAP, the specific marker of glia cells (Fig. 4b, 3) in the cells after neurogenic induction. Fourteen days after MAPCs were programmed to differentiate into hepatocytes, the spindle-shaped cells (Fig. 4c, 1) turned into round or oval shape and became wider and larger, with narrowed intercellular junctions and appearance of cell patches (Fig. 4c, 2). Immunofluorescence analysis showed that the induced cells expressed albumin, the marker of hepatocytes (Fig. 4c, 3). The above findings suggested that clonal cultured MAPCs were able to differentiate into osteoblasts, adipocytes, neuronal cells, and hepatocytes under proper culture conditions.

\section{Discussion}

There is increasing evidence that isolation strategies of stem cells differ for different source tissues and different stem cell types; even though the tissue is from the same source, different isolating protocols may obtain different stem cell a
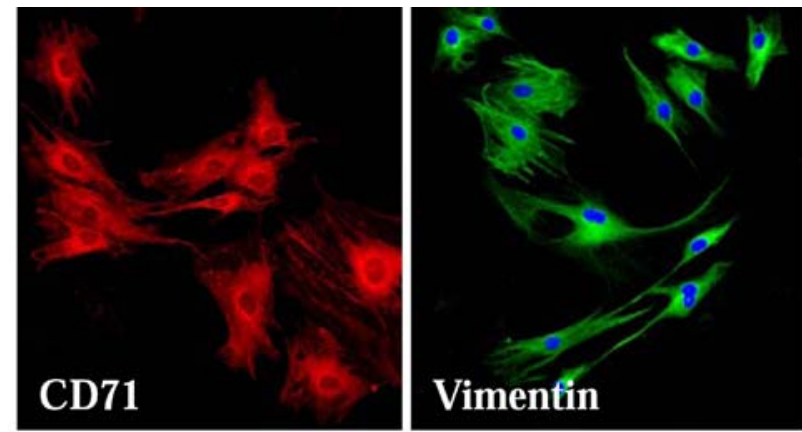

b
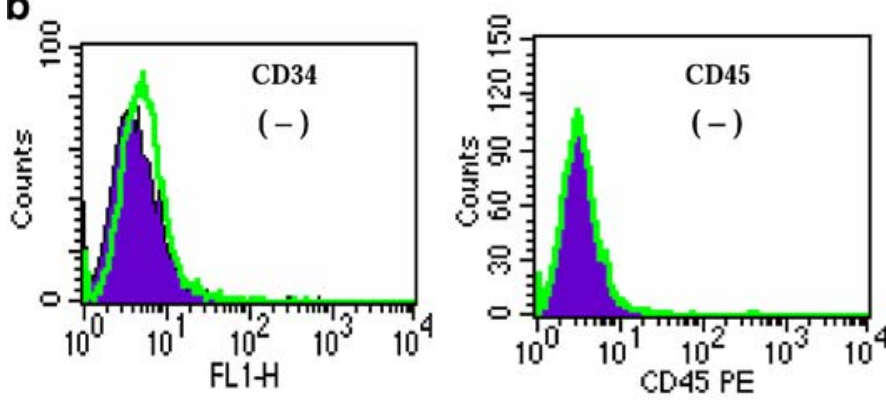

Fig. 3 a Expression of cell markers in the cloned MAPCs. Immunofluorescence analyses of single cell-derived P20 MAPCs10D\# were positive for CD71, Vimentin (with nuclear counterstained
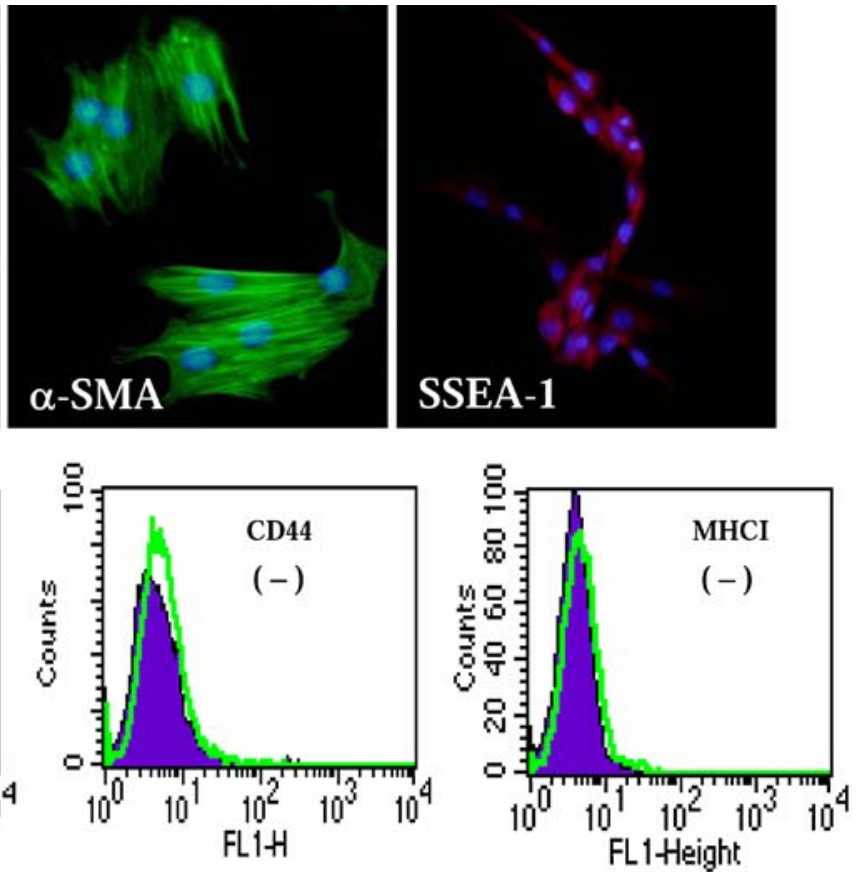

by Hochest33342), $\alpha$-SMA and SSEA-1 (with nuclear counterstained by DAPI, all original magnification $\times 200$ ). b FACS analysis: P4 MAPCs were negative for CD34, CD45, CD44, and MHC-I antigen 

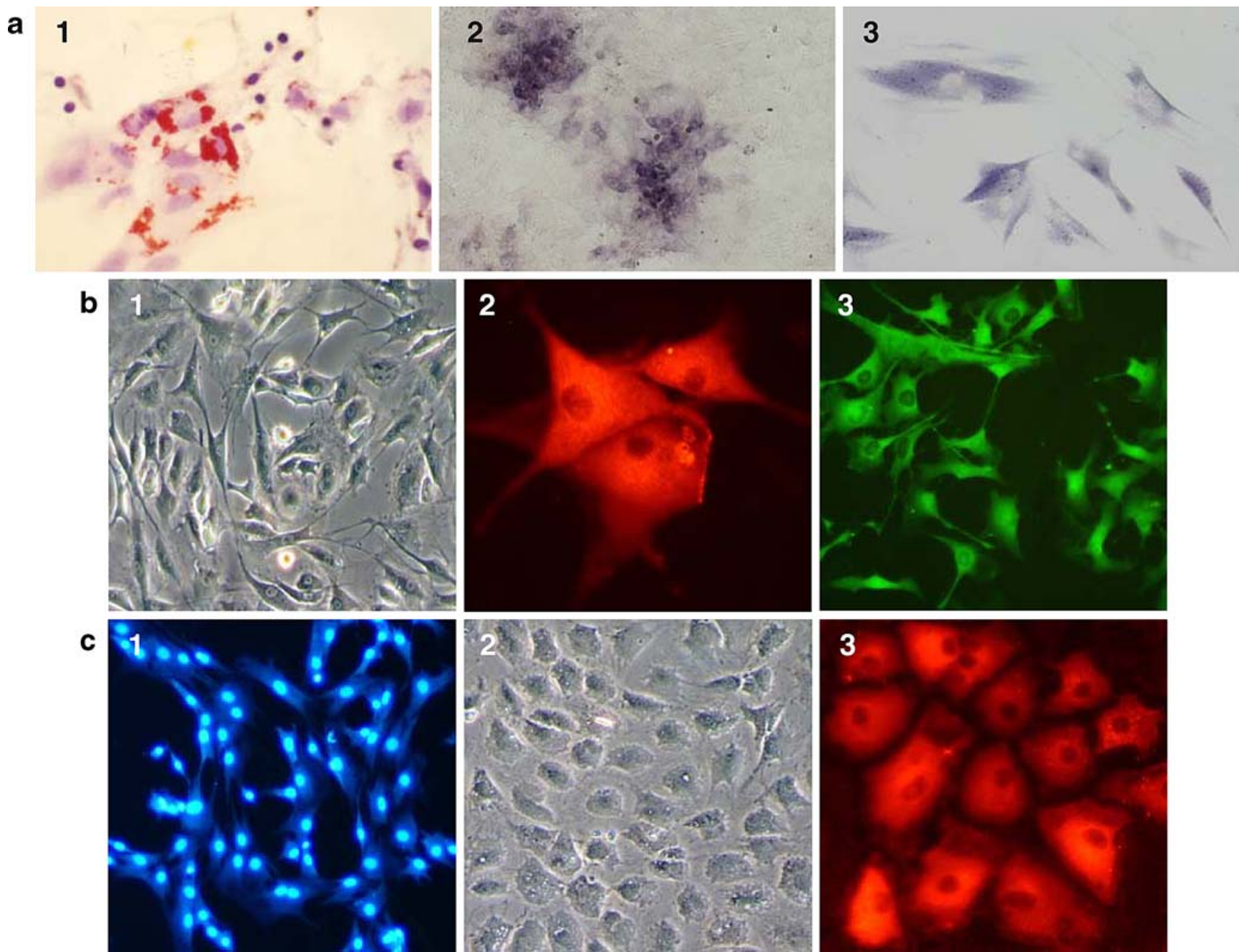

Fig. 4 Differentiation of cloned 10D\# MAPCs into three somatic germ layers. a Differentiation into adipogenic-like cells and osteogenic-like cells. 1 differentiated MAPCs were positive in oil red $\mathrm{O}$ staining counterstained with hematoxylin; 2 and 3 differentiated MAPCs were positive for alkaline phosphatases (AKP staining) and osteopontin (immunocytochemical staining). b Differentiation into neuronal-like cells. 1 Under phase microscope, apparent branches were observed to grow out from the spindle-shaped cells. 2 and 3

Immunofluorescence staining showed the presence of GFAP and Tau protein. c Differentiation into hepatocytes-like cells. 1 DAPI counterstaining showed that the MAPCs untreated with hepatogenic medium retained the spindle shape. 2 MAPCs turned from spindle into round or oval after hepatogenic induction. 3 Immunofluorescence analysis showed expression of albumin in differentiated MAPCs (all original magnification $\times 200$ )

types [17]. For example, stromal stem cells screened out with different molecular markers demonstrated certain varieties in growth and plasticity, and were therefore given different names, including MSCs [18-19], MAPCs [10-12], MPCs (mesodermal progenitor cells) [20], and marrowisolated adult multi-lineage inducible cells (MIAMI) [21]. In the present study, we used culture conditions similar to those of Verfaillie's team and successfully obtained a comparatively homogeneous population of MAPCs through the following protocol: isolating mononuclear cells from rat total bone marrow by direct adherence, eliminating nonadherent cells after three to four passages, subjecting the remaining cells to single cell clonal culture by limiting dilution technique, plating the cells at a low density of 250 cells $/ \mathrm{cm}^{2}$ for further passage, and finally screening for clonelike cells. We found that single cell-derived MAPCs did not express CD34, CD45, CD44, and MHC-I, which was consistent with the results of Verfaillie's team, who found that MAPCs were able to reserve their pluripotency when plated at a low density, and unable to do so when plated at a much higher density. With pluripotency decreasing, CD44 and MHC I turned from negative to strongly positive in MAPCs, and therefore could serve as a marker for the loss of pluripotency. It should be notified that our protocol for MAPC isolation, which involved direct adherence, passage selection, single cell clonal culture and low density passage, is less complicated and more economical than that of Verfaillie's team, who employed the technique of immuno- 
magnetic microbeads. The reliability of our protocol is verified by its results. Single cell-derived MAPCs retained their multi-potential differentiation capability even after being passaged for 20 generations, and could not only give rise to adipocytes and osteoblasts (mesoderm) but to neurons, glia cells (ectoderm), and hepatocytes (endoderm).

It has been demonstrated that the isolation method and cultivation condition are vital to the isolation of bone marrow stem cells and the maintenance of stem cell property [16]. The latest research showed that in vitro culture of human MSCs with autologous serum is superior to FBS for the amplification and for maintaining the pluripotency of MSCs [22], and the original culture strategy might lead to the loss of differentiation potential of MSCs. Moreover, some researchers found that serum-free culture could upgrade the differentiation potential of MSCs [23]. So recently, researchers have made persistent efforts to optimize the isolation method of MSCs. For example, people have isolated another population of pluripotent cells, called marrow-isolated adult multilineage inducible (MIAMI) cells, from human bone marrow by plating whole bone marrow cells initially in media containing 5\% FBS and subsequently maintaining them in the medium containing $2 \%$ FBS in fibronectin-coated dishes. These cultures were then maintained in hypoxic conditions at $1,300-1,400 \mathrm{cells} / \mathrm{cm}^{2}$ [20]. MIAMI cells still expressed telomerase, Oct-4, and Rex-1 even after being expanded for more than 50 population doublings. In the present study, our medium contained a low level of serum, but was supplemented with growth factor and LIF, which promoted the proliferation of MAPCs to some extent and retained their dedifferentiated state. Single cell clonal culture and low density passage may help to isolate a more homogenous cell population with strong proliferation capability.

As the marker for pluripotent stem cells, Oct-4 is closely linked with the pluripotency of MAPCs [24]. Our results showed that single cell-derived MAPCs not only highly expressed Oct-4 but expressed the early markers of endoderm, mesoderm, and ectoderm: CYP51, SM22 $\alpha$ A [14], GATA4 [25], and NMDA [26], which is the molecular basis for their differentiation into three germ layers. Woodbury's team [16] demonstrated that MSCs expressed germline, ectodermal, endodermal, and mesodermal genes before neurogenesis. The present research extended their observations. Our observations confirm that single cell-derived MAPCs transcribe Oct4 and genes of the three germ layers simultaneously, and could differentiate into multiple lineages. It may be concluded that under appropriate circumstances, single cell-derived MAPCs can maintain not only characteristics of stem cells but multi-lineage differentiation potential which has expressed corresponding regulating genes, and single cell-derived MAPCs could differentiate into multiple lineages through quantitative modulation of regulating gene expression, rather than switching on expression of specific genes.

Acknowledgments This work was supported by grants from the National Natural Science Foundation of China (No. 30600651) and the Cooperation Foundation for Overseas Young Scientists (No. 30428001). We would like to thank professor JIANG Yuehua from the University of Minnesota Medical School for his valuable advice. We also thank ZHANG Jun from Changhai Hospital of the Second Military Medical University for technical assistance in FACS analysis and YU Danghui from the Second Military Medical University Press for revision of the English language.

\section{References}

1. Shim WS, Jiang S, Wong P, Tan J, Chua YL, Tan YS, Sin YK, Lim CH, Chua T, Teh M, Liu TC, Sim E (2004) Ex vivo differentiation of human adult bone marrow stem cells into cardiomyocyte-like cells. Biochem Biophys Res Commun 324 (2):481-488

2. Song L, Tuan RS (2004) Transdifferentiation potential of human mesenchymal stem cells derived from bone marrow. FASEB J 18 (9):980-982

3. Wagers AJ, Weissman IL (2004) Plasticity of adult stem cells. Cell 116(5):39-648

4. Priller J (2003) Robert Feulgen Prize Lecture. Grenzganger: adult bone marrow cells populate the brain. Histochem Cell Biol 120 (2):85-91

5. Goodell MA (2003) Stem-cell 'plasticity': befuddled by the muddle. Curr Opin Hematol 10(3):208-213

6. Rodic N, Rutenberg MS, Terada N (2004) Cell fusion and reprogramming: resolving our transdifferences. Trends Mol Med 10(3):93-96

7. Spees JL, Olson SD, Ylostalo J, Lynch PJ, Smith J, Perry A, Peister A, Wang MY, Prockop DJ (2003) Differentiation, cell fusion, and nuclear fusion during ex vivo repair of epithelium by human adult stem cells from bone marrow stroma. Proc Natl Acad Sci U S A 100(5):2397-2402

8. Wang X, Willenbring H, Akkari Y, Torimaru Y, Foster M, AlDhalimy M, Lagasse E, Finegold M, Olson S, Grompe M (2003) Cell fusion is the principal source of bone-marrow-derived hepatocytes. Nature 422(6934):897-901

9. Kirschstein R, Skirboll LR(2001) Stem cells: Scientific progress and future research directions. Report Prepared by The National Institutes of Health 45-46

10. Jiang YH, Jahagirdar BN, Lee Reinhardt R, Schwartz RE, Dirk Keenek C, Ortiz-Gonzalezk XR, Reyes M, Lenvik T, Lund T, Blackstad M, Du J, Aldrich S, Lisberg A, Lowk WC, Largaespada DA, Verfaillie CM (2002) Pluripotency of mesenchymal stem cells derived from adult marrow. Nature 418(6893):41-49

11. Jiang YH, Vaessen B, Lenvik T, Blackstad M, Reyes M, Verfaillie CM (2002) Multipotent progenitor cells can be isolated from postnatal murine bone marrow, muscle, and brain. Exp Hematol 30(8):896-904

12. Reyes M, Verfaillie CM (2001) Characterization of multipotent adult progenitor cells, a subpopulation of mesenchymal stem cells. Ann N Y Acad Sci 938:231-235

13. Prockop DJ (2002) Adult stem cells gradually come of age. Nat Biotechnol 20(8):791-792

14. Zhang FB, Li L, Fang B, Zhu DL, Yang HT, Gao PJ (2005) Passage-restricted differentiation potential of mesenchymal stem cells into cardiomyocyte-like cells. Biochem Biophys Res Commun 336(3):784-792 
15. Neubauer M, Fischbach C, Bauer-Kreisel P, Lieb E, Hacker M, Tessmar J, Schulz MB, Goepferich A, Blunk T (2004) Basic fibroblast growth factor enhances PPARg ligand-induced adipogenesis of mesenchymal stem cells. FEBS Letters 577(1-2):277-283

16. Woodbury D, Reynolds K, Black IB (2002) Adult bone marrow stromal stem cells express germline, ectodermal, endodermal, and mesodermal genes prior to neurogenesis. J Neurosci Res 69 (6):908-917

17. Ulloa-Montoya F, Verfaillie CM, Hu WS (2005) Culture systems for pluripotent stem cells. J Biosci Bioeng 100(1):12-27

18. Pittenger MF, Mackay AM, Beck SC, Jaiswal RK, Douglas R, Mosca JD, Moorman MA, Simonetti DW, Craig S, Marshak DR (1999) Multilineage potential of adult human mesenchymal stem cells. Science 284(5411):143-147

19. Tropel P, Noel D, Platet N, Legrand P, Benabid AL, Bergera F (2004) Isolation and characterisation of mesenchymal stem cells from adult mouse bone marrow. Exp Cell Res 295(2):395-406

20. Reyes M, Lund T, Lenvik T, Aguiar D, Koodie L, Verfaillie CM (2001) Purification and ex vivo expansion of postnatal human marrow mesodermal progenitor cells. Blood 98(9):2615-2625

21. 'Ippolito GD, Diabira S, Howard GA, Menei P, Roos BA, Schiller PC (2004) Marrow-isolated adult multilineage inducible (MIAMI) cells, a unique population of postnatal young and old human cells with extensive expansion and differentiation potential. J Cell Sci 117(Pt 14):2971-2781

22. Kobayashi T, Watanabe H, Yanagawa T, Tsutsumi S, Kayakabe M, Shinozaki T, Higuchi H, Takagishi K (2005) Motility and growth of human bone-marrow mesenchymal stem cells during ex vivo expansion in autologous serum. J Bone Joint Surg Br 87 (10):1426-1433

23. Pochampally RR, Smith JR, Ylostalo J, Prockop DJ (2004) Serum deprivation of human marrow stromal cells (hMSCs) selects for a subpopulation of early progenitor cells with enhanced expression of OCT-4 and other embryonic genes. Blood 103(5):1647-1652

24. Nichols J, Zevnik B, Anastassiadis K, Niwa H, Klewe-Nebenius D, Chambers I, Scholer H, Smith A (1998) Formation of pluripotent stem cells in the mammalian embryo depends on the POU transcription factor Oct4. Cell 95(3):379-391

25. Molkentin JD, Lin Q, Duncan SA, Olson EN (1997) Requirement of the transcription factor GATA4 for heart tube formation and ventral morphogenesis. Genes Dev 11(8):1061-1072

26. Kumar KN, Tilalaratne N, Johnson PS, Allen AE, Michaelis EK (1991) Cloning of cDNA for the glutamate binding subunit of an NMDA receptor complex. Nature 354(6348):70-73 